\title{
Rabdomiolisis y ampollas del coma debido a una poliintoxicación aguda
}

\section{Rhabdomyolysis and coma blisters}

\section{due to acute poliintoxication}

Mujer de 35 años, consumidora de alcohol, cocaína y neurolépticos. Ingresa en el hospital en situación de coma, con respuesta a estímulos dolorosos, tras intento de autolisis (ingesta de 12 comprimidos de amoxicilina, 60 de quetiapina, 500 cc de aguardiente, 2 cervezas y cocaína no cuantificada) en las horas previas. En la piel se apreciaban placas eritematosas, edematosas, bien delimitadas en cadera, dorso de articulaciones interfalángicas y pies, que en pocas horas evolucionaron formando ampollas tensas de contenido claro (figuras 1 y 2). La analítica mostró elevación de CPK (15013 UI/L; CN: 10-50), creatinina $(1,51 \mathrm{mg} / \mathrm{dl} ; \mathrm{CN}: 0,6-1,1)$ y presencia de mioglobinuria. La biopsia de ampolla de piel mostró desprendimiento epidérmico, sin inflamación dérmica (figura 3). Las glándulas sudoríparas muestran necrosis en sombra con plegamiento de la membrana basal (figura 4). Con reposición hidroelectrolítica y forzado de diuresis la evolución fue favorable con desaparición de las lesiones cutáneas y las alteraciones analíticas en pocos días.

La necrosis de glándulas sudoríparas en la piel es muy característica de hipoxia de cualquier causa ya que son muy sensibles a ésta. La rabdomiolisis se produce en situaciones de ingesta de fármacos o drogas (alcohol, cocaína), alteraciones metabólicas, isquemia y otras causas.

La asociación de lesiones cutáneas y rabdomiolisis en el coma se ha descrito en algunas ocasiones. El mecanismo patogénico no está bien aclarado y puede ser multifactorial, si bien se considera que la hipoxia generalizada y local están involucradas en ambas entidades.

Las erupciones cutáneas en pacientes en coma pudieran ser un marcador importante para la presencia de rabdomiolisis.

\section{Bibliografía}

1. Bagley WH, et al. Rhabdomyolysis. Intern Emerg Med. 2007; 39: 390-2

2. Sánchez-Yus E, et al. Histopathology of cutaneous changes in drug-induced coma. Am J Dermatopathol. 1993; 15: 208-16

3. Miyamoto T, et al. Cutaneous eruption in coma patients with nontraumatic rhabdomyolysis. Dermatology. 2001; 203: 233-7

\section{Diagnóstico}

Rabdomiolisis y ampollas del coma debido a una poliintoxicación aguda

Margarita Carnero Fernández¹, Carmen Fachal Bermúdez². 'Unidad de Hospitalización a Domicilio, ${ }^{2}$ Servicio de Anatomía Patológica. Complejo Hospitalario Universitario de Vigo (CHUVI). SERGAS. Vigo

Como citar este artículo: Carnero Fernández M, Fachal Bermúdez C.

Rabdomiolisis y ampollas del coma debido a una poliintoxicación aguda. Galicia Clin 2012; 73 (4): 181 Recibido: 16/9/2012; Aceptado: 29/10/2012
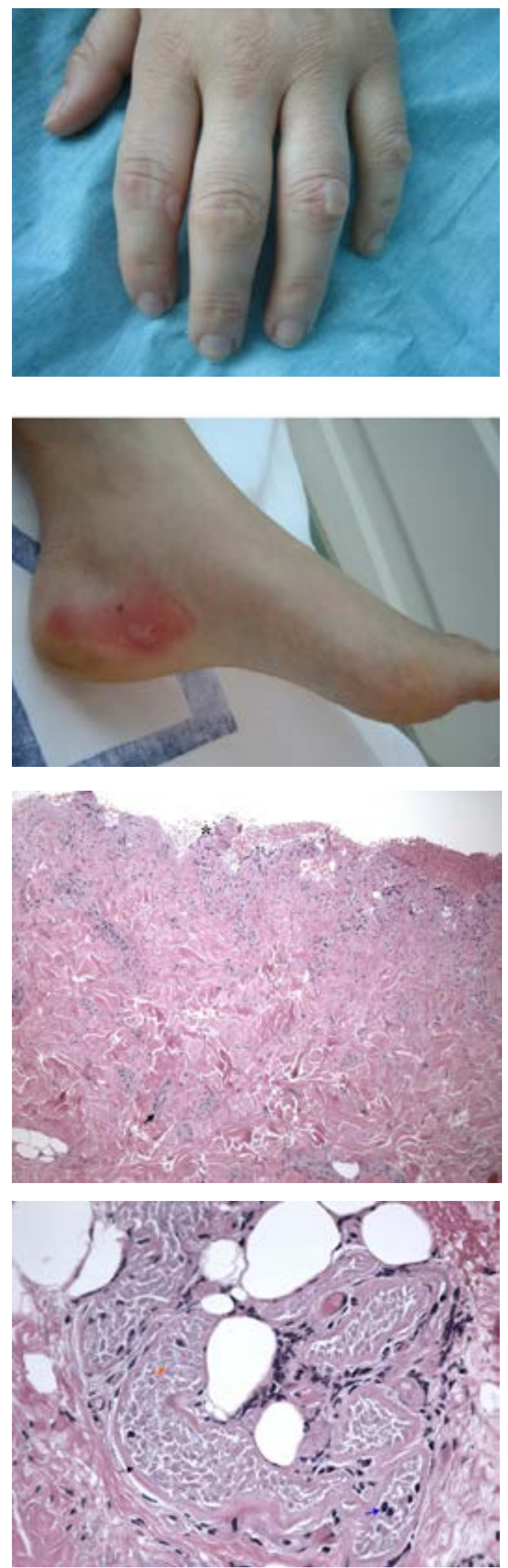